\section{B A Institute of \\ YK Business Administration \\ 六下 \\ Karachi \\ Leadership and Ideas for Tomorrow}

Business Review

Volume 5 Issue 1 January-June 2010

$1-1-2010$

\title{
Uses pattern of cosmetics and perception of personality: A study of students doing professional courses in Lucknow city
}

\author{
Ruchi Srivastava \\ Motilal Rastogi School of Management, Lucknow, UP India \\ D.S. Chaubey \\ Institute of Management and Technology, Lucknow, UP India
}

Follow this and additional works at: https://ir.iba.edu.pk/businessreview

Part of the Applied Behavior Analysis Commons, Art Education Commons, and the Personality and Social Contexts Commons

\section{(c) (9)}

This work is licensed under a Creative Commons Attribution 4.0 International License.

\section{Recommended Citation}

Srivastava, R., \& Chaubey, D. (2010). Uses pattern of cosmetics and perception of personality: A study of students doing professional courses in Lucknow city. Business Review, 5(1), 159-170. Retrieved from https://doi.org/10.54784/1990-6587.1263 


\title{
CASE STUDY
}

\section{Uses Pattern of Cosmetics and Perception of Personality: A study of Students doing Professional Courses in Lucknow City}

\author{
Ruchi Srivastava \\ Motilal Rastogi School of Management, Lucknow, UP India \\ D.S. Chaubey \\ Institute of Management and Technology, Lucknow, UP India
}

\begin{abstract}
The modern, urban Indian populations both male and female are becoming increasingly conscious about their style and looks, with great emphasis on lightening of skin tone. Skin care and color cosmetics have witnessed solid growth for the last few years Within a short span of the last five-six years, the use of cosmetics by Indian consumers has increased significantly with more and more women and men taking greater interest in personal grooming. Increasing disposable incomes, changing life styles, influence of satellite television and greater product choice and availability has also fueled the consumption pattern of cosmetics to build the perception of self image and personality. The ecological understanding of perception advanced from Gibson's early work is perception-in-action, the notion that perception is a requisite property of animate action, without perception action would not be guided and without action perception would be pointless. The purpose of this study was to investigate the effect of cosmetics use on attribution concerning the likelihood of provoking psychological benefit in improving the personality. The study reported here forms part of an investigation of what psychological benefits, if any, exist for the user of cosmetics. A central theme in the work on physical attractiveness is that if one is physically attractive one is assumed to have a more ideal personality than someone of lesser attractiveness. If cosmetics really do make people look more physically attractive, then with the use of cosmetics others should perceive people more favourably in terms of personality characteristics. This study, therefore, attempted to find out whether cosmetics really do improve appearance ratings (by males and females) and in result improve ratings of personality
\end{abstract}

Post liberalisation period in India is witnessing rapid socio- economic changes. The life style marketing has emerged as one of the important strategy for marketer to attract consumer to its offer. The study of lifestyle is interdisciplinary. It draws on a variety of disciplines such as anthropology, psychology, sociology and economics. Marketing uses this eclectic approach for segmenting, targeting and positioning which forms the core of marketing strategy. Cosmetics and toiletries are not just the domain of women any longer and Indian men too are increasingly taking to the use of more and more body sprays, perfumes and other cosmetics and toiletries. With rising demand from men, the Indian market is getting enlarged and many players are coming out with cosmetic products especially skin care products for men. 


\section{Review of Previous Literature}

The concept of 'self' is important in forming an understanding of consumer behaviour (Schutte and Ciarlante, 1998). Self-concept in consumer behaviour is a psychological process. Self-concept consists of whatever individuals consider to be theirs, including their body, family, possessions, moods, emotions, conscience, attitudes, values, traits and social positioning (Rolando, 1998). Both Eastern and Western cultures perceive the 'self' concept from the point of inner private self and outer public self. According to Mooij (2004), the concept of self is 'independent' in individualistic cultures whereas in collectivistic cultures self is regarded as interdependence. Jean Ann Graham and A. J. Jouhar(1980)in his study on interpersonal attraction, others' perceptions of the physically attractive and self-perception shows that, although cosmetics have been used, inter alia, to manipulate physical attractiveness in some of these experiments, there are little data showing benefit of cosmetics per se to the individual. Few systematic studies have examined individual differences in women's use of facial make-up or the possible psychosocial effects of such use. In an study of the role of cosmetics in selfimage enhancement and social impression management a survey was done on fortytwo female college students, differential use was associated with a number of selected personality variables-public self-consciousness, public body-consciousness, social anxiety, and various body-image factors. Study revealed more self-confident and sociable when wearing as opposed to not wearing their customary cosmetics. Malhotra (2003) in his study describes the main reasons for boom in cosmetic industry as increasing fashion and beauty consciousness coupled with rising incomes and focus on health and fitness. To complement this, beauty - culture or cosmetology has emerged as a major occupational avenue with significant commercial potential. New scientific developments, techniques, products and media hype, has contributed the Indian fashion industry in generating mega revenues and this has in turn added to the growth of cosmetic industry. Rising hygiene and beauty consciousness due to changing demographics and lifestyles, deeper consumer pockets, rising media exposure, greater product choice, growth in retail segment and wider availability are the reasons reported by (Euromonitor International, 2006). Over recent years, India has seen increasing literacy levels, penetration of satellite television, growing urbanization and greater beauty awareness among women, which has resulted in rewarding growth opportunities to cosmetics and toiletries manufacturers. Rebecca Nash, George Fieldman, Trevor Hussey, Jean-Luc Lévêque, Patricia Pineau (2006) in his work Cosmetics: They Influence More Than Caucasian Female Facial Attractiveness explored whether 4 Caucasian women would be evaluated differently on 4 social measures depending on whether they were presented with or without makeup. Participants - 152 men and 171 women - were split into 2 groups and were presented with the women's facial photographs either with or without cosmetics. Women presented wearing cosmetics were perceived as healthier and more confident than when presented without. Participants also awarded women wearing makeup with a greater earning potential and with more prestigious jobs than the same women without cosmetics. Briney ( 2004a ) describes an interesting trend among Indian 


$\overline{\text { Business Review - Volume } 5 \text { Number } 1}$ January - June 2010

cosmetic consumers, while other global countries are taking to the traditional Indian herbal and Ayurvedic applications for beauty solutions, Indian consumers are increasingly looking to international personal care brands as lifestyle enhancement products, in the belief that the association with and use of an international brand confers one with a sophisticated and upper class image. The urban population in the major cities with increasing purchasing power is the main force that drives demand for various cosmetic products in India. The advent of satellite television and awareness of the western beauty and fashion world, advertisements and promotions, increasing number of women joining the work force is changing preferences, customs and cultures in India. The success of contestants from India at various well known international beauty pageants in the last few years have also contributed towards making the Indian women more conscious about looks, beauty, grooming and aware of western cosmetic products/brands. All this changed the needs and consumption pattern of the Indian consumer, thus leading to increased growth in the cosmetic sector. More Indian consumers started using cosmetics and a small segment are also seen willing to pay a little more to look good. Increasing disposable income and purchasing power have led to a constant up-gradation from mass to premium products even though mass-market products still constitute the major portion of the India cosmetics and toiletries market. Since liberalization in 1991 along with the crowning of many Indian women at international beauty pageants, the cosmetic industry has come into the limelight. Consequently there has been a change in the cosmetic consumption and this trend is fueling growth in the cosmetic sector. Indians by and large are price-sensitive. Indian consumers want the best but many are not always willing to pay for it. Understanding the attitudes, preferences and aspirations of the different segments of India's consuming class is very crucial to achieving success in the Indian market.

Objective of Study: General Objective of the study The main objective of the study is to analyze the purchase pattern of cosmetic consumers in Lucknow.

\section{Specific Objectives}

1) To describe the demographic profile of cosmetic consumers.

2) To study the perception of student toward the uses pattern of cosmetics.

3) To assess the role of celebrities in influencing influencing the purchasing pattern of cosmetics among student of Lucknow city.

4) To analyze the different factors involved in purchase decision of cosmetics.

5) To study the spending pattern of cosmetic consumers and its influence on society.

\section{Research Methodology}

The present study is an exploratory research study. In order to study the consumer perception towards uses of cosmetics both primary and secondary data were collected. Secondary data was collected from different magazines, newspapers and 
Internet. The primary data is collected through questionnaire using survey method. For this purpose 50 male students and 50 female students (Total 100students) were randomly selected. An attempt was made to check their attitude towards uses pattern of cosmetics and their perception of personality. Certain attributes were rated on five-point scale and the final score has been calculated by using weighted ranking method. The data thus received was tabulated, analyzed and appropriate results was drawn. Univariate and Bivariate data analysis techniques were used to analyze the data.

The following hypothesis was constructed for analyzing the data:-

Hypothesis No 1: Uses pattern of cosmetics by the consumers is independent of their gender categories

Hypothesis no 2: Different media influencing the customer in particular brand selection is independent with the gender categories

Hypothesis no 3 Main purpose of using the cosmetics is independent with the gender categories

Hypothesis No4: The impact of cosmetics in developing personality is independent of the professional status of the respondents.

\section{Scope of the Study}

Though the study represent the uses pattern of cosmetics among the students doing professional courses At Lucknow city, due to very small sample size, the finding may not be a true representation and it can not be generalized but it will give a better prospect for future study and may have a wide application in future.

\section{Analysis and Discussion}

\section{a. Age wise Classification of Respondents}

\begin{tabular}{|l|l|c|c|}
\hline S1 No & Description & No of Respondents & $\%$ \\
\hline A & Upto 20 Years & 47 & 47 \\
\hline B & 21to 25 Years & 38 & 38 \\
\hline C & Above 25 Years & 15 & 15 \\
\hline & Total & 100 & 100 \\
\hline
\end{tabular}

Age analysis of respondents indicates that most of respondents falls in the age group upto 20 years as it was indicated by 47 percent respondents in the sample. The respondents in the age group of 21-25 year accounts for 38 percent and the remaining 15 percent respondents falls in the age group of above 25 years. 


\section{b. Educaton Level of Respondents}

\begin{tabular}{|l|l|c|c|}
\hline S1 No & Level of Education & No of Respondents & $\%$ \\
\hline A & Upto Intermediate & 31 & 31 \\
\hline B & Upto graduation & 51 & 51 \\
\hline C & Post graduate and Above & 18 & 18 \\
\hline & Total & 100 & 100 \\
\hline
\end{tabular}

The information related to educational qualifications of the respondents indicates that most of the respondents were having graduate degree to their credit as it was indicated by $51 \%$ respondents in the sample. As many as $18 \%$ respondents are having education up to post graduation and others. Only $31 \%$ respondents were having education qualification upto intermediate only.

\section{c. Income Level wise Classification of Respondents}

\begin{tabular}{|l|l|c|c|}
\hline S1 No & Level of Income & No of Respondents & $\%$ \\
\hline A & Upto 5000PM & 23 & 23 \\
\hline B & 5000-10000PM & 29 & 29 \\
\hline C & Above 10000PM & 48 & 48 \\
\hline & Total & 100 & 100 \\
\hline
\end{tabular}

Data relating to the income of the respondents indicated that as many as 23 percent respondents were from the monthly income group of up to Rs. 5000 per month. 29 percent respondents were having monthly family income between Rs.5000 to Rs 10000 per month and 48 percent respondent were having more than Rs. 10000 monthly income.

\section{d. Type of Course Doing at Present.}

\begin{tabular}{|l|l|c|c|}
\hline S1 No & Type of Course & No of Respondents & $\%$ \\
\hline A & $\begin{array}{l}\text { Undergraduate } \\
\text { Professional courses }\end{array}$ & 63 & 63 \\
\hline B & Post graduate & & \\
\hline & professional courses & 37 & 37 \\
\hline & Total & 100 & 100 \\
\hline
\end{tabular}

an attempt was made to know the type of professional courses undertaken by the students. Information thus received indicates that 63 percent respondents belongs to those categories who are doing under graduate professional courses. 37 percent respondent of the sample is doing post graduate professional courses. 


\section{e. Uses Pattern of Cosmetics}

\begin{tabular}{|l|l|c|c|}
\hline S1 No & Uses Pattern & No of Respondents & $\%$ \\
\hline A & Using cosmetics & 86 & 86 \\
\hline B & Do not use cosmetics & 14 & 14 \\
\hline & Total & 100 & 100 \\
\hline
\end{tabular}

the information presented in the above table indicates that sample is dominated by those respondents who use cosmetics as it was indicated by $86 \%$ respondents in the sample. In comparison to this $14 \%$ respondent in the sample indicated that they do not use cosmetics.

\section{f. Main Source of Information}

\begin{tabular}{|l|l|c|c|}
\hline S1 No & $\begin{array}{l}\text { Main Source of } \\
\text { Information }\end{array}$ & No of Respondents & $\%$ \\
\hline A & $\begin{array}{l}\text { Advertisement in } \\
\text { various media }\end{array}$ & 47 & 47 \\
\hline B & Friends & 31 & 31 \\
\hline C & Family members & 12 & 12 \\
\hline D & Sales agents & 07 & 07 \\
\hline E & Others & 03 & 03 \\
\hline & Total & 100 & 100 \\
\hline
\end{tabular}

Analysis indicates that advertisement is one of the powerful tools and is most helpful in creating the information about the various brands as it was indicated by $47 \%$ respondent in the sample. Almost one third respondents in the sample (31\%) have got information from their friends. Family member account for $12 \%$ respondent in the sample. Sales agent were able to create information in $7 \%$ respondents. $3 \%$ respondent indicated other media to get information about various brands.

\section{G. Major influencer in Brand Selection}

\begin{tabular}{|l|l|c|c|c|}
\hline S1 No & Main Source of Information & Male & Female & $\begin{array}{c}\text { No of } \\
\text { Respondents }\end{array}$ \\
\hline A & Advertisement in various media & 17 & 12 & 29 \\
\hline B & Friends & 11 & 14 & 25 \\
\hline C & Family members & 15 & 16 & 31 \\
\hline D & Sales agents & 4 & 7 & 11 \\
\hline E & Others & 3 & 1 & 04 \\
\hline & Total & 50 & 50 & 100 \\
\hline
\end{tabular}

\footnotetext{
$\left(X^{2}\right)=3.072509$
} 
Analysis of the data presented in the above table indicates that out of 100 respondent 29 respondents were mainly influenced by advertisement in selecting a particular brand. 25 respondents were influenced by their friends. 31 respondents were mainly influenced by family members. Sales agent were able to influence to $11 \%$ respondents. Remaining 4\% indicated other medium of their influences. Analysis also indicated that in comparison to female, male member were more influenced by advertisement. It also reveals that female members were most influenced by family member, friends and sales agents. The calculated value of the Chi Square test statistics $\left(\div^{2}\right)=3.072509$ at 5 percent level of significant is lesser than the tabulated value (5.99) with 2 degree of freedom. Thus, the hypothesis that uses pattern of cosmetics among the students is independent with the gender categories.

\section{h. Occasion of Using Cosmetics}

\begin{tabular}{|l|l|c|c|}
\hline S1 No & Level of Income & No of Respondents & $\%$ \\
\hline A & When I go for the college & 34 & 34 \\
\hline B & When I go to the party & 28 & 28 \\
\hline C & Whenever I leave my home & 16 & 16 \\
\hline D & On all the occasion & 22 & 22 \\
\hline & Total & 100 & 100 \\
\hline
\end{tabular}

The information presented in the above table indicates the occasion of using cosmetics. The data reveals that little less than one third of the respondent in the sample are of the opinion that they use cosmetics whenever they go to any party as it was indicated by $28 \%$ respondents in the sample. More than one third students of the sample $(34 \%)$ indicated that they use cosmetics whenever they go to college. $16 \%$ student are of the opinion that they use cosmetics whenever they leave home . however $22 \%$ respondents are indicated that they use it on all the occasion.

\section{Uses Pattern}

\begin{tabular}{|l|l|c|c|c|c|}
\hline $\begin{array}{l}\text { Sl No } \\
\text { A }\end{array}$ & Uses Pattern & Male & Female & No of Respondents & $\%$ \\
\hline B & Medium Users & 14 & 7 & 55 & 55 \\
\hline C & Light User & 13 & 11 & 21 & 21 \\
\hline & Total & 23 & 32 & 100 & 24 \\
\hline
\end{tabular}

$\left(\mathrm{X}^{2}\right)=3.972727$

The information pertaining to the uses pattern of cosmetics reveals that $55 \%$ respondents belongs to heavy users of cosmetics. $21 \%$ accounts for medium user and $24 \%$ belongs to light users of cosmetics. Analysis also indicates that in comparison to male female tends to be more heavy cosmetic user. On the other hand male students are 
more inclined towards medium and light users. The calculated value of the Chi Square test statistics $\left(\mathrm{X}^{2}\right)=3.972727$ at 5 percent level of significant is lesser than the tabulated value (9.488) with 4 degree of freedom. Thus, the hypothesis that different media influencing the customer in particular brand selection is independent with the gender categories.

\section{j. Main purpose of using Cosmetics}

\begin{tabular}{|l|l|c|c|c|}
\hline Sl No & Main purpose of Using Cosmetics & Male & Male & No of Respondents \\
\hline A & To look good & 7 & 17 & 24 \\
\hline B & For taking care of body & 11 & 8 & 19 \\
\hline C & For self satisfaction & 13 & 04 & 17 \\
\hline D & For creating impression on others & 18 & 15 & 33 \\
\hline E & Perception of improving personality & 01 & 06 & 07 \\
\hline & Total & 50 & 50 & 100 \\
\hline
\end{tabular}

$\left(\mathrm{X}^{2}\right)=13.24921$

Analysis indicates that creating impression on other seems to be the main purpose of using the cosmetics by the students in Lucknow area as it was indicated by $33 \%$ respondent in the sample. $24 \%$ respondents are of the opinion that they use cosmetics to look good. $19 \%$ respondent indicated that they use it for taking care of their body. $17 \%$ respondent revealed that they use cosmetics for their self satisfaction. Remaining 7 percent respondents indicated that they use cosmetics for improving personality. Analysis also reveals that female are more inclined to use cosmetics with perception of looking good and improving personality as compare to the male. In comparison to this male are more inclined to use cosmetics with the objective of taking body care, for self satisfaction and creating impression on others. The calculated value of the Chi Square test statistics $\left(\div^{2}\right)=13.24921$ at 5 percent level of significant is greater than the tabulated value $(9.488)$ with 4 degree of freedom. Thus, the hypothesis that main purpose of using the cosmetics is dependent with the gender categories.

\section{k. Cosmetics boosting the level of confidence}

\begin{tabular}{|l|l|c|c|}
\hline S1 No & Level of Income & No of Respondents & $\%$ \\
\hline A & Using cosmetics & & \\
\hline & help in increasing confidence & 88 & 88 \\
\hline B & Does not increase confidence & 12 & 12 \\
\hline & Total & 100 & 100 \\
\hline
\end{tabular}

The data presented in the above table indicates that most of the respondents are of the opinion that application of cosmetics is helpful in building their confidence as it was indicated by $88 \%$ respondent in the sample. In comparison to this only $12 \%$ respondents are of the opinion that this does not help them in increasing the confidence at all. 


\section{Use Of Cosmetics Help In Creating The Strong First Impression On Others}

\begin{tabular}{|l|l|c|c|}
\hline S1 No & Level of Income & No of Respondents & $\%$ \\
\hline A & $\begin{array}{l}\text { Use of cosmetics help in } \\
\text { creating the strong first } \\
\text { impression on others }\end{array}$ & 63 & 63 \\
\hline B & $\begin{array}{l}\text { Use Of Cosmetics does not } \\
\text { Help In Creating The Strong } \\
\text { First Impression On Others }\end{array}$ & 30 & 30 \\
\hline C & Cant say & 07 & 07 \\
\hline & Total & 100 & 100 \\
\hline
\end{tabular}

Analysis indicates that almost two third respondent (63\%) are of the opinion that Use of cosmetics help in creating the strong first impression on others. In comparison to this 30\% respondent does not support the statement and feel that it does not help in creating the strong impression on others. Remaining 7\% respondent did not were not sure about it.

\section{m. Cosmetics has become an essential ingredient for personality Development}

\begin{tabular}{|l|l|c|c|c|c|}
\hline Sl No & Description & Male & Female & No of Respondents & $\%$ \\
\hline A & Yes & 37 & 32 & 69 & 69 \\
\hline B & No & 13 & 18 & 31 & 31 \\
\hline & Total & 50 & 50 & 100 & 100 \\
\hline
\end{tabular}

$$
\left(X^{2}\right)=1.16877
$$

Analysis indicates that more than two third respondents are of the opinion that cosmetics has become an essential ingredient for personality development as it was indicated by $69 \%$ respondent in the sample. In comparison to this $31 \%$ respondents say that it is not essential ingredients for personality development. Analysis also projects that in comparison to female member, more male's members are of the opinion that cosmetics has become essential ingredient for personality development. It is also evident from the table that more female are of the opinion that cosmetics is not an essential ingredients for personality development. The calculated value of the Chi Square test statistics $(\div 2)=1.16877$ at 5 percent level of significant is lesser than the tabulated value (3.841) with 1 degree of freedom. Thus, the hypothesis that impact of cosmetics in developing personality is independent of the gender categories of students doing professional courses at Lucknow. 


\section{Conclusion}

Post liberalisation period in India is witnessing rapid socio- economic changes. The life style marketing has emerged as one of the important strategy for marketer to attract consumer to its offer. The study of lifestyle is interdisciplinary Increasing disposable incomes, changing life styles, influence of satellite television and greater product choice and availability has also fueled the consumption pattern of cosmetics to build the perception of self image and personality. The ecological understanding of perception advanced from Gibson's early work is perception-in-action, the notion that perception is a requisite property of animate action, without perception action would not be guided and without action perception would be pointless. The purpose of this study was to investigate the effect of cosmetics use on attribution concerning the likelihood of provoking psychological benefit in improving the personality. The study reported here forms part of an investigation of what psychological benefits, if any, exist for the user of cosmetics. A central theme in the work on physical attractiveness is that if one is physically attractive one is assumed to have a more ideal personality than someone of lesser attractiveness. If cosmetics really do make people look more physically attractive, then with the use of cosmetics others should perceive people more favourably in terms of personality characteristics. This study, therefore, attempted to find out whether cosmetics really do improve appearance ratings (by males and females) and in result improve ratings of personality. The study indicates that more than one third students of the sample (34\%) indicated that they use cosmetics whenever they go to college. The study also reveals that different media influencing the customer in particular brand selection is independent with the gender categories. The analysis signifies that the main purpose of using the cosmetics is dependent with the gender categories of respondents. It also shows that the impact of cosmetics in developing personality is independent of the gender categories of students doing professional courses at Lucknow.

\section{References}

Schutte, H. and Ciarlante, D. (1998) Consumer Behaviour in Asia, Macmillan Press Limited

Jean Ann Graham and A. J. Jouhar. (1981) The effects of cosmetics on person perception. International Journal of Cosmetic Science 3:5, 199-210

Rebecca Nash, George Fieldman, Trevor Hussey, Jean-Luc Lévêque, Patricia Pineau (2006) in his work Cosmetics: They Influence More Than Caucasian Female Facial Attractiveness, Journal of Applied Social Psychology 36 (2) , 493-504 doi:10.1111/j.00219029.2006.00016.x

Psychology and Marketing, Pages 531 - 548

Malhotra, Pervin (2003, May 2). The Beauty of Being a Beautician. Chandigarh, The Tribune.

Monteiro, Noella. Report Date: 04/04/2003

Schiffman, L. G and Kanuk, L. Leslie. (1994) Consumer Behaviour, NJ: Prentice Hall. 
Uses Pattern of Cosmetics and Perception of Personality: A study of Students doing Professional Courses in Lucknow City

Dr. D.S. Chaubey

Ms. Ruchi Srivastava

1. Name :

2. Age :

3. Educational Qualification :

Upto Matriculate

Graduate
Intermediate

Post Graduate and others

4. Family Income(Per Month) :
Upto Rs. 5000/-
Rs. 5000/- to Rs. 10000/-
Rs. 10000/- and above

5. What type of course you are doing at present

a. Undergraduate Professional courses b. Post graduate professional courses

6. Do you use cosmetics
a. Yes
b. No

7. From where did you get information about cosmetics Advertisement in various media
a. Friends
c. Sales agents
$\square \quad$ b. Family members
d. Others

8. Who influenced you most in selecting a particular cosmetics brand
a. Advertisement in various media
b. Friends
c. Family members
d. Sales agents
e. Others

9. On what occasion do you generally use cosmetics
a. When I go for the office
b. When I go to the party
c. Whenever I leave my home
d. For all the reasons

10. Describe yourself as a user of cosmetics
a. Heavy user
b. Medium user
c. Light user
d. Do not use 
11. Do you feel that the use of cosmetics help to increase your confidence
a. Yes
b. No

12. The spending on cosmetics helps to increase your confidence
a. Yes
b. No

13. What is the main purpose of using the cosmetics
a. To look good
c. For self satisfaction

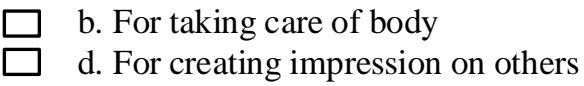
e. Perception of improving personality

14. The use of cosmetics help in creating the strong First impression on others
a. Yes
b. No

15.Cosmetics has become an essential ingredient for personality Development a. Yes b. No

That is the peril of the knowledge society; its promise is that it will be the first society in which ordinary common people - and that means most people - do not earn their daily bread by the sweat of their brow. It is the first society in which 'honest work' does not mean a callused hand. This is far more than a social change. "It is a change in the human condition."

Peter F. Drucker Managing in a Time of Great Change 